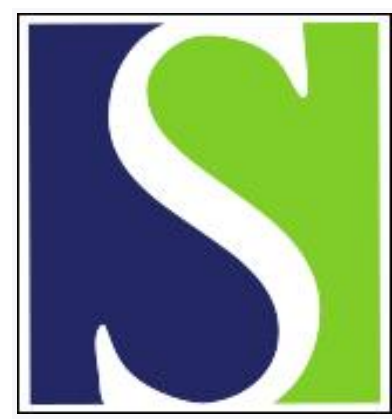

Scand J Work Environ Health 2005;31(1):15-29

https://doi.org/10.5271/sjweh.844

Issue date: Feb 2005

Disentangling the causal relationships between work-home interference and employee health

by van Hooff MLM, Geurts SAE, Taris TW, Kompier MAJ, Dikkers JSE, Houtman ILD, van den Heuvel FMM

Affiliation: Radboud University Nijmegen, Department of Work and Organizational Psychology, PO Box 9104, 6500 HE Nijmegen, The Netherlands. m.vanhooff@psych.ru.nl

The following articles refer to this text: 2006;32(6):421-430; 2014;40(1):66-73; 2017;43(2):109-116; 2018;44(1):69-79

Key terms: causal relationship; depressive complaint; employee health; fatigue; longitudinal data; police officer; work-home interference; work-family conflict

This article in PubMed: www.ncbi.nlm.nih.gov/pubmed/15751615 


\title{
Disentangling the causal relationships between work-home interference and employee health
}

\author{
by Madelon LM van Hooff, MA, ${ }^{1}$ Sabine AE Geurts, PhD, ${ }^{1}$ Toon W Taris, PhD, ${ }^{1}$ Michiel AJ Kompier, \\ PhD, ${ }^{1}$ Josje SE Dikkers, MA, ${ }^{1}$ Irene LD Houtman, PhD, ${ }^{2}$ Floor MM van den Heuvel, MA ${ }^{2}$
}

\begin{abstract}
van Hooff MLM, Geurts SAE, Taris TW, Kompier MAJ, Dikkers JSE, Houtman ILD, van den Heuvel FMM. Disentangling the causal relationships between work-home interference and employee health. Scand J Work Environ Health 2005;31(1):15-29.
\end{abstract}

\begin{abstract}
Objectives The present study was designed to investigate the causal relationships between (time- and strainbased) work-home interference and employee health. The effort-recovery theory provided the theoretical basis for this study.

Methods Two-phase longitudinal data (with a 1-year time lag) were gathered from 730 Dutch police officers to test the following hypotheses with structural equation modeling: (i) work-home interference predicts health deterioration, (ii) health complaints precede increased levels of such interference, and (iii) both processes operate. The relationship between stable and changed levels of work-home interference across time and their relationships with the course of health were tested with a group-by-time analysis of variance. Four subgroups were created that differed in starting point and the development of work-home interference across time.

Results The normal causal model, in which strain-based (but not time-based) work-home interference was longitudinally related to increased health complaints 1 year later, fit the data well and significantly better than the reversed causal model. Although the reciprocal model also provided a good fit, it was less parsimonious than the normal causal model. In addition, both an increment in (strain-based) work-home interference across time and a long-lasting experience of high (strain-based) work-home interference were associated with a deterioration in health.

Conclusions It was concluded that (strain-based) work-home interference acts as a precursor of health impairment and that different patterns of (strain-based) work-home interference across time are related to different health courses. Particularly long-term experience of (strain-based) work-home interference seems responsible for an accumulation of health complaints.
\end{abstract}

Key terms depressive complaints; fatigue; longitudinal data; police officers; work-family conflict.

Nowadays many employees have difficulty combining work and domestic obligations. Empirical research has consistently shown that work demands interfere with private life (ie, work-home interference) more often than the other way around (ie, home demands interfering with worklife). [See Frone (1) and Geurts \& Demerouti (2) for reviews.] In light of the higher prevalence of workhome interference, we have focused our study exclusively on work-home interference and more specifically on the temporal relationship between work-home interference and employee health.
In the literature, three different types of work-home interference have been distinguished (3). Time-based work-home interference develops when the time devoted to work obligations makes it physically impossible to meet obligations in the private domain (eg, when long workhours interfere with participation in family activities). Strain-based work-home interference refers to the process in which tension developed at work is transferred to the home domain (eg, when people have difficulty relaxing at home after a stressful workday). Behavior-based work-home interference refers to a situation

1 Radboud University Nijmegen, Nijmegen, The Netherlands.

2 TNO Work and Employment, Hoofddorp, The Netherlands.

Correspondence to: Madelon LM van Hooff, Radboud University Nijmegen, Department of Work and Organizational Psychology, PO Box 9104, 6500 HE Nijmegen, The Netherlands. [E-mail: m.vanhooff@psych.ru.nl] 
in which specific behavior expected at work is incompatible with behavior expected at home (eg, teachers who continue to act as teachers with their own children). Previous research has shown that especially time- and strain-based work-home interference are negatively associated with employee health. [See Allen et al (4) for a meta-analysis.] Therefore, in our study, we focused on these two types of work-home interference.

\section{Previous research}

A considerable amount of knowledge has been gathered on work-home interference and its presumed consequences $(1,2)$. A recent meta-analysis (4) showed that work-home interference was particularly associated with stress-related outcomes. In fact, the highest weighted mean correlations were found for burnout $\left(\mathrm{r}_{\mathrm{w}}=0.42\right)$, work-related stress $\left(r_{\mathrm{w}}=0.41\right)$, and depressive complaints $\left(r_{w}=0.32\right)$. However, one notable weakness of previous research on work-home interference is that the findings mainly rely on cross-sectional data; in other words, as yet little insight into the causal nature of these relationships has been gathered.

To demonstrate such relationships, a longitudinal design is required. The small number of longitudinal studies that have examined the relationship between work-home interference and employee health nonetheless provide mixed results with respect to the causal direction of effects. It has been found that work-home interference acts as a precursor of heavy alcohol use (but not as a precursor of depressive complaints) over a 4year period (5) and as a precursor of decreased levels of (self and co-worker) reported well-being over a 6month period (6). In contrast, the results of a 6-month longitudinal study (7) showed that strain-based workhome interference was a result rather than a precursor of stress complaints. Finally, a recent study (8) showed that work-home interference was related to various indicators of well-being 1 year later, but only for women.

Although, in field studies, the use of a longitudinal design is a precondition for mapping causal relationships, it is not a sufficient condition (in fact, we can never fully prove causality, we can only bring up evidence that makes such relations plausible). In their critical consideration of longitudinal research, Taris \& Kompier (9) have pointed towards the importance of the theoretical plausibility of the presumed causal relationship. It is important that researchers specify the process that underlies a particular, presumably causal association-the mere significance of an across-time correlation is not enough to make us believe that there is a causal relationship between two concepts.

This issue embodies a second limitation of previous research on work-home interference. Many studies (including several longitudinal ones) that addressed the relationship between work-home interference and employee health were not guided by a strong theoretical framework that sheds light on the underlying (psychological or physiological) mechanisms. [See, for example, Geurts \& Demerouti (2) and Geurts et al (10).] Often studies confine themselves to the presentation of significant regression weights, suggesting that health scores are "predicted" by work-home interference and possibly other concepts. If a theory was used, it was predominantly based on role stress theory (11). In research inspired by this theory, it remains unclear, however, how work-home interference should be embedded in the classical stressor-stress-strain relationship. Some researchers consider work-home interference as a stressor $(12,13)$, whereas others view it as an indicator of strain $(14,15)$ or an intervening variable in the stressor-strain relationship (16). Moreover, from the role stress perspective, no assumptions can be made concerning the impact of a long-lasting experience of workhome interference on employee health. Yet it would seem particularly interesting to know how worker health develops in response to persistent exposure to high levels of work-home interference.

A third inadequacy that applies, in particular, to previous longitudinal research in the field of occupational health psychology (including the domain of work-home interference) (9) is that it leaves indistinctness concerning causality. For the most part, no attention is paid to the existence of possible reciprocal relationships (eg, from work-home interference to health complaints and from health complaints to work-home interference), which requires the use of a full-panel design (ie, both independent and dependent variables are measured at all measurement points). A notable exception is a recent study conducted by Demerouti et al (17), who examined the reciprocal relations among work pressure, workhome interference, and exhaustion in a three-phase, full panel study with time lags covering a period of 6 weeks. Although they found support for normal and reversed causal relationships between work-home interference and exhaustion, their study could not shed light on the long-term temporal relationships between work-home interference and health, as the time intervals between the phases were too short. Moreover, even if reciprocal effects are tested with a full-panel design, "it is still impossible to exclude the possibility that particular associations are due to variables that were not measured in the study design [p 1]" (9). The inconsistent and often inconclusive results from longitudinal studies in this area may be, at least partly, caused by the impact of these (often unmeasured) third variables (18).

A fourth and insufficiently acknowledged constraint that also applies to longitudinal research within the area of occupational health psychology is that it examines a 
process that proceeds in time with often arbitrarily chosen measurement points. This constraint implies that it is unknown at exactly what point in time the measurement process begins. According to Kasl \& Jones (19, p 9), we put an "arbitrary temporal window" on a "steadystate cohort" that may include the following three types of workers: (i) those who are studied "too early" (ie, the process has not started yet), (ii) those who are studied "too late" (ie, the effects of the process are already observed at the first measurement point), and (iii) those for whom the "temporal window is just right". Also, in our current study, the level of work-home interference or health complaints may already be high for some of the participants in the first phase, whereas, for others, these levels may be low at this point in time. Furthermore, some workers may have gone through a change in experienced work-home interference (eg, from low work-home interference to high work-home interference or from high work-home interference to low workhome interference) during the observation period, whereas the situation of others may be characterized by stable levels of high or low work-home interference. A closer examination of theoretically derived subgroups (9) that are characterized by different work-home interference starting points and courses across time (8, 20) will probably yield more insight into the processes that may underlie the longitudinal relationships between work-home interference and employee health.

We designed our study to overcome these theoretical and methodological shortcomings [ie, the use of cross-sectional designs (i), the lack of theory (ii), unclear causality (iii), and the neglect of different workhome interference starting points and courses across time (iv)]. Therefore, in our study, we examine the relationship of work-home interference with two health indicators (ie, fatigue and depressive complaints), (i) by using a two-phase longitudinal full-panel design with a 1-year time lag, (ii) by including a relevant theoretical perspective [ie, the effort-recovery model (21)], (iii) by addressing possible reciprocal relationships while controlling for the impact of potential third variables, and (iv) by studying the development of health complaints in theoretically derived subgroups of workers that have different starting points and courses across time with respect to work-home interference. A distinction is made between time-based and strain-based work-home interference in order to determine whether the two types of work-home interference have a similar or a different relationship with health.

\section{Theoretical framework}

To date, various theoretical perspectives, such as role stress theory (11) and, to a less extent, the conservation of resources theory (22) have been employed to examine the relationship between work-home interference and its health consequences. [See Geurts \& Demerouti (2) for an overview.] We believe that another theoretical framework, namely, the effort-recovery model (21), may shed more light on the mechanisms that underlie the relationship between long-lasting work-home interference and employee health (10). According to this work psychological model, effort expenditure at work not only has benefits in terms of productivity, but also short-term psychological and physiological costs. Under normal circumstances, these costs or negative load effects are reversible (ie, when effort is no longer expended, the psychobiological systems that were activated stabilize within a certain period of time to a baseline level). This process is called recovery. One of the central assumptions of the effort-recovery model is that effort expenditure at work is likely to have adverse health consequences when the opportunities to recuperate during (ie, internal recovery) or after (ie, external recovery) the work period are insufficient. Internal recovery is, for instance, jeopardized when workers unremittingly expend effort at work without the possibility to take an occasional break or to alternate strenuous tasks with tasks that require less effort. External recovery may be endangered, for instance, when effort expenditure is prolonged and recovery time is insufficient because demands continue to exist after worktime (eg, due to extensive domestic obligations) or when workers are slowly unwinding. In this latter situation, also referred to as "sustained activation" (23), load effects built up at work do not unfold immediately, but instead last during nonwork time (eg, when workers have difficulty to relax after a demanding work period) (24). When (internal or external) recovery is insufficient, the worker, still in a suboptimal state, has to invest additional (compensatory) effort to perform adequately during the next work period, which may result in an increased intensity of load effects that make an even higher demand on the recovery process. Eventually, insufficient recovery results in an accumulation of negative load effects that, in the long run, may seriously affect health [eg, prolonged fatigue, sleep deprivation, and manifest health problems $(25,26)]$.

Drawing on the effort-recovery model, we define work-home interference as "a process in which a worker's functioning and recovery at home are hampered by negative load effects that have built up at work [p 536]" (10). Note that work-home interference is defined here in terms of recovery in that a high level of such interference implies that recovery during nonwork time is impeded due to insufficient recovery time (ie, timebased work-home interference) or the transfer of workrelated strain to the home domain (ie, strain-based work-home interference). 


\section{Study population and methods}

\section{Study population}

The data used in this study were originally collected as part of a two-phase longitudinal survey on the etiology of burnout and depressive complaints among members of the Dutch police force. At time 1 (1999) a random sample of 10000 employees was drawn from the whole population of police personnel in The Netherlands. Of this number, 5277 police officers (response rate of 53\%) completed a questionnaire that included questions about work characteristics, work-home interference, and health. Of these respondents, 2732 (response rate of $52 \%$ ) agreed to participate in the follow-up study, which took place 1 year later (year 2000). The police officers who had already reported a (very) high level of burnout complaints (27) at time 1 were excluded from further participation in the study, as those with a history of burnout in the first phase could not offer insight into the incidence and etiology of burnout (19). To determine whether the level of burnout complaints was (very) high, a comparison was made with an independent representative sample of the Dutch work force (28), and the police officers with a 75th percentile score or higher on all three burnout components (ie, $\geq 2.20$ on exhaustion, $\geq 2.00$ on distance, and $\leq 3.66$ on competence) were excluded. This procedure resulted in a sample of 1667 participants who did not suffer from serious burnout complaints in the first phase of the study. From this sample, a random sample of 1000 employees was contacted for the follow-up study, of which 828 (response rate of $83 \%$ ) completed a second questionnaire (that was highly similar to the first questionnaire). An analysis of variance revealed several differences between the time-1 scores of those who agreed to participate in the follow up-study and those who did not (the nonresponse group, $\mathrm{N}=2545$ ). Women and those with lower salary levels agreed less often to participate than did men and those with higher salary levels. This result matched earlier findings concerning the characteristics of nonrespondents in comparison with those of respondents. [See Taris (29) for a review.] Furthermore, in the response group higher scores on exhaustion (change in mean score $=0.09, \mathrm{P}<0.05)$ and lower competence scores were observed (change in mean score $=0.16, \mathrm{P}<0.05$ ) than those of the nonresponse group; this finding suggests that those with relatively high levels of burnout complaints (but not as high levels as those of the workers already excluded) considered it more important to contribute to the follow-up study than did the group with fewer complaints.

The analyses in our study were based on the longitudinal part of the original study, meaning that our sample consisted of 828 of a possible 1000 participants (ie, the number of workers contacted for the time- 2 follow-up study), implying a response rate of $82.2 \%$ for our study. We restricted our analyses to those employed full-time in both phases of the study and thus excluded at least one potential confounder (ie, part-time versus full-time status) of the relationship between work-home interference and health $(30,31)$. The final sample therefore consisted of 730 full-time police employees $(91 \%$ male and $9 \%$ female, with a mean age at time 1 of 42.3 (SD 7.7) years, a mean experience at time 1 of 20.4 (SD 9.0) years, and a mean of 10.5 (SD 8.5) years in the present job. Eighty-six percent were employed in executive police work ( $47 \%$ base police force, $14 \%$ research squad, $4 \%$ foreign police, $3 \%$ traffic police, $15 \%$ other), and $14.4 \%$ were in the administrative or technical support services. In the second phase, $21 \%$ of the participants reported that they had experienced a change in their work situation (ie, changed job type or police force) since the first phase, and a similar proportion $(21 \%)$ went through a change in their family situation (eg, birth of a child, a child leaving the house, marriage, or divorce) in-between the two phases.

\section{Hypotheses}

We conducted our study in two parts. In the first part we investigated the temporal relationship between timeand strain-based work-home interference and health complaints. From the perspective of the effort-recovery model, we hypothesized that relatively high levels of time- and strain-based work-home interference at time 1 are related to increased levels of fatigue and depressive complaints 1 year later (hypothesis 1a). In order to determine whether work-home interference acts primarily as a precursor of health complaints or as an outcome of health complaints as well (eg, a higher level of work-home interference is experienced due to poor health and a diminished capacity to deal with high workload), we also tested the reversed causal pathways. An alternative (but not per se competing) hypothesis is, therefore, that relatively high levels of fatigue and depressive complaints at time 1 are associated with increased levels of time- and strain-based work-home interference 1 year later (hypothesis $1 b$ ).

In the second part of this study, we examined the course of health complaints as a function of stable and changed levels of time- and strain-based work-home interference. To map this process, we created four subgroups that differed in their starting point and development of work-home interference across time. This approach was inspired by that of de Lange et al (20), who studied the across-time effects of work characteristics on employee health in a similar way. We expect that workers who reported a high level of work-home interference at both points in time (ie, stable high group) also 
experienced more health complaints (at both points in time) than workers who reported a relatively low level of work-home interference (hypothesis 2). Moreover, because this "stable high group" was characterized by a long-term (at least 1-year) experience of relatively high work-home interference (indicating insufficient recovery), health complaints should have been aggravated over time for this particular subgroup (hypothesis 3 ). We expected the subgroup that reported a low level of workhome interference at both points in time (ie, stable low group) to experience fewer health complaints than workers who reported a relatively high level of work-home interference (hypothesis 4) without any significant change in health over time.

A third subgroup was characterized by an increase in work-home interference across time, that is, by the experience of low work-home interference at time 1 and a relatively high level of work-home interference 1 year later (ie, change-from-low-to-high group). According to the effort-recovery model, we expected that a deterioration of health in this group could be observed (hypothesis 5). Finally, the fourth subgroup was characterized by a favorable change in work-home interference across time, namely, by the experience of high work-home interference at time 1 , and low work-home interference 1 year later (ie, change-from-high-to-low group). Because of the decrease in work-home interference during the 1-year period, we expected to observe a decrease in health complaints in this subgroup over time (hypothesis 6).

\section{Measures}

Work-home interference. Time-based and strain-based work-home interference were each measured with four items from the SWING (ie, the Survey Work-home Interaction-NijmeGen) (31-33). These scales measure the extent to which employees believe that their functioning at home is hampered by work demands. The four items covering time-based work-home interference are "How often does it happen that..." (i) "you have to cancel appointments with your spouse/family/friends due to work-related commitments?", (ii) "your work schedule makes it difficult for you to fulfill your domestic obligations?", (iii) "your work takes up time that you would have liked to spend with your spouse/family/ friends?", and (iv) "you have to work so hard that you do not have enough time for any of your hobbies?" The four items measuring strain-based work-home interference are "How often does it happen that..." (i) "you are irritable at home because your work is demanding?", (ii) "you do not fully enjoy the company of your spouse/ family/friends because you worry about your work?", (iii) "you find it difficult to fulfill your domestic obligations because you are constantly thinking about your work?", and (iv) "your work obligations make it difficult for you to feel relaxed at home?". For both of these work-home interference scales, the respondents answered on a four-point scale $[0=($ almost $)$ never, 1 = sometimes, 2 = often, and 3 = always], with higher scores reflecting higher levels of work-home interference. The Cronbach alphas were 0.73 (time 1) and 0.76 (time 2) for time-based work-home interference, and for strain-based work-home interference the corresponding values were 0.77 (time 1) and 0.81 (time 2).

Fatigue. Fatigue was measured with five items from a Dutch adaptation of the Maslach Burnout InventoryGeneral Survey (28); the items were developed to measure the exhaustion component of burnout. Example items are "I feel fatigued when I get up in the morning and have to face another day on the job" and "I feel used up at the end of the workday" ( $0=$ never, $6=$ always $)$, higher scores indicating higher levels of complaints. As workers with (very) high scores on this scale in phase 1 were excluded from our study, we considered the term "exhaustion" to be inappropriate to describe the (only low to moderate) scores on this scale and preferred to use the term "fatigue". The Cronbach alphas were 0.71 (time 1) and 0.83 (time 2).

Depressive complaints. Depressive complaints were measured with eight items of a Dutch translation of the short version (Iowa form) of the Center for Epidemiologic Studies Depression (CES-D) scale $(34,35)$. Each participant was offered brief statements of feelings or behaviors and was asked to indicate how often he or she felt that way during the last 2 weeks. Examples are "I felt depressed", "I was happy" (reversed), and "I felt everything I did was an effort" ( 1 = seldom, 2 = sometimes, 3 = mostly), higher scores signifying higher levels of depressive complaints. The Cronbach alphas were 0.78 (time 1) and 0.80 (time 2).

Covariates. In order to ensure that the statistical association between work-home interference and each health indicator was not due to third variables, the impact of two important job characteristics (ie, workload and job control, time 1 measures only) was controlled. (Workhours had already been controlled by the inclusion of only participants who worked on a full-time basis during both phases.) Both constructs were measured by subscales from NOVA-WEBA $(36,37)$, a Dutch questionnaire developed to identify risk factors for work stress. The psychometric qualities (ie, reliability, validity, and factor structure) of this instrument have been tested with satisfactory results (38). Workload was measured with five items from a Dutch-modified version of the psychological demands scale of the Job Content Questionnaire $(39,40)$. A typical question is "Do you have to work very fast?". The Cronbach alphas were 
0.73 (time 1) and 0.74 (time 2). Each question could be answered by "no" (0) or "yes" (1), higher scores indicating higher levels of workload. As the items from the Job Content Questionnaire were originally constructed with four response categories $(1=$ strongly disagree to $4=$ strongly agree), the psychometric properties of this modified version have been tested and considered satisfactory (41).

Job control was measured with nine items (one was derived from the Job Content Questionnaire (39), three were borrowed from a Dutch questionnaire on organizational stress (VOS-D, 42), and five were self-developed by the authors of the NOVA-WEBA) that again could be answered by "no" (0) or "yes" (1), higher scores reflecting higher levels of job control. An exemplary item is "Do you have a choice in deciding how to do your work?" The Cronbach alpha was 0.78 for both phases. In addition to these two job characteristics, respondent gender $($ male $=0$, female $=1)$ and age (in years) were included as covariates.

Reported job and family changes. In the follow-up questionnaire (time 2), the respondents were asked whether changes had occurred in (i) their job type, (ii) the police force they were participating in, or (iii) their family circumstances since they responded to the first questionnaire. The response categories were "yes" and "no". If the participants responded positively (yes), they were asked to specify their current job type, police force, or family condition. With respect to the last, the participants could indicate whether their current situation had changed during the last year in terms of, for example, marriage, divorce, the birth of a child, a child leaving the house, moving in with parents, or a spouse entering or leaving the labor market.
The means and standard deviations of all the survey measures, as well as the correlations between the measures and the t-values regarding the across-time differences, are presented in table 1.

\section{Analyses}

Preliminary analyses. At first (step 1), it was important to examine whether the four core variables under study (ie, time-based work-home interference, strain-based work-home interference, fatigue, and depressive complaints) were indeed empirically distinct constructs. Therefore, in each phase, we examined the fit of several models for the relations among the items of these core variables using confirmative factor analysis (43). In the first model, all the items were constrained to load on only one latent factor. In the second, we created two latent factors, one for the items that measured work-home interference (irrespective of the type of interference) and one for the items that measured health (irrespective of the type of complaints). In the third, an additional distinction was made between fatigue and depressive complaints, the result being three latent factors. In the fourth model, four factors were created in line with the four core variables under study.

As it cannot be excluded that relations between work-home interference and health are influenced by actual changes in the job type, the police force, and the family circumstances, an additional analysis was conducted to determine whether the relationships among all eight variables under study (ie, the four core variables and the four covariates) were the same for all the participants, irrespective of these changes. Therefore, using the LISREL 8.30 program (43), we tested a model in which the covariance matrices (ie, the relations

Table 1. Correlations, means, standard deviations (SD), and results of the t-tests for the core variables and covariates of the study. $\left(\mathrm{WHI}=\right.$ work-home interference, $\mathrm{T}_{1}=$ time $1, \mathrm{~T}_{2}=$ time 2$)$

\begin{tabular}{|c|c|c|c|c|c|c|c|c|c|c|c|c|c|c|c|c|}
\hline & Mean & SD & $t^{a}$ & 1 & 2 & 3 & 4 & 5 & 6 & 7 & 8 & 9 & 10 & 11 & 12 & 13 \\
\hline 1. Time-based WHI $\mathrm{T}_{1}$ & 0.87 & 0.47 & & 1.00 & & & & & & & & & & & & \\
\hline 2. Time-based WHI $\mathrm{T}_{2}$ & 0.86 & 0.48 & -0.94 & $0.62^{b}$ & 1.00 & & & & & & & & & & & \\
\hline 3. Strain-based WHI $T_{1}$ & 0.68 & 0.44 & & $0.46^{b}$ & $0.37^{b}$ & 1.00 & & & & & & & & & & \\
\hline 4. Strain-based WHI $\mathrm{T}_{2}$ & 0.71 & 0.47 & 1.93 & $0.30^{\mathrm{b}}$ & $0.48^{b}$ & $0.62^{b}$ & 1.00 & & & & & & & & & \\
\hline 5. Fatigue $T_{1}$ & 1.09 & 0.55 & & $0.25^{b}$ & $0.20^{b}$ & $0.50^{b}$ & $0.34 \mathrm{~b}$ & 1.00 & & & & & & & & \\
\hline 6. Fatigue $T_{2}$ & 1.21 & 0.76 & $4.67^{b}$ & $0.17^{b}$ & $0.29^{b}$ & $0.37^{b}$ & $0.51^{b}$ & $0.47^{b}$ & 1.00 & & & & & & & \\
\hline 7. Depressive complaints $T_{1}$ & 1.18 & 0.27 & & $0.09 \mathrm{c}$ & 0.06 & $0.26^{b}$ & $0.19^{b}$ & $0.33^{b}$ & $0.25^{b}$ & 1.00 & & & & & & \\
\hline 8. Depressive complaints $T_{2}$ & 1.21 & 0.29 & $2.75^{b}$ & $0.10^{c}$ & $0.12^{b}$ & $0.23^{b}$ & $0.30^{b}$ & $0.18^{b}$ & $0.41^{\mathrm{b}}$ & $0.40^{b}$ & 1.00 & & & & & \\
\hline 9. Workload $\mathrm{T}_{1}$ & 0.58 & 0.33 & & $0.31^{b}$ & $0.32^{b}$ & $0.33^{b}$ & $0.27^{b}$ & $0.29^{b}$ & $0.22^{b}$ & 0.07 & 0.03 & 1.00 & & & & \\
\hline 10. Workload $\mathrm{T}_{2}$ & 0.56 & 0.34 & -1.66 & $0.30^{b}$ & $0.35^{b}$ & $0.35^{b}$ & $0.37^{b}$ & $0.24^{b}$ & $0.32^{b}$ & 0.05 & $0.09^{c}$ & $0.63^{b}$ & 1.00 & & & \\
\hline 11. Job control $T_{1}$ & 0.73 & 0.26 & & $0.18^{b}$ & $0.14^{b}$ & 0.03 & 0.02 & $0.08^{c}$ & $0.08^{c}$ & 0.07 & 0.04 & $0.14^{b}$ & $0.11^{\mathrm{b}}$ & 1.00 & & \\
\hline 12. Job control $T_{2}$ & 0.74 & 0.25 & -1.68 & $0.14^{b}$ & $0.17^{\mathrm{b}}$ & 0.04 & $0.09^{c}$ & 0.04 & $0.15^{b}$ & 0.07 & $0.11^{\mathrm{b}}$ & $0.11^{\mathrm{b}}$ & $0.14^{b}$ & $0.62^{\mathrm{b}}$ & 1.00 & \\
\hline 13. Gender & - & - & - & $-0.08^{c}$ & -0.07 & $-0.12^{b}-$ & $-0.08^{c}$ & -0.03 & 0.07 & 0.04 & $0.10^{c}$ & $-0.09^{c}$ & -0.05 & 0.07 & $0.09^{c}$ & \\
\hline 14. Age & 42.3 & 7.68 & - & $-0.08^{c}$ & $-0.10^{\mathrm{b}}$ & $0.12^{b}$ & $0.09^{c}$ & 0.03 & 0.00 & 0.05 & 0.02 & 0.06 & 0.05 & $0.15^{\mathrm{b}}$ & $0.19^{b}$ & $-0.38^{\mathrm{b}}$ \\
\hline
\end{tabular}

a Due to occasional missing values, the degrees of freedom ranged from 697 to 729 for this comparison. A repeated measures multiple analysis of variation revealed that, in general, there were differences across time for these variables: $F(6,677)=6.28, P<0.01$.

b $\mathrm{P}<0.05$.

c $P<0.01$. 
among all the variables) were set equal across four groups of workers, that is, (i) those who reported no change in their work or family situation versus those who did report such changes, namely, (ii) a change in the work situation, (iii) a change in the family situation, or (iv) a change in both domains.

Causal relations (hypotheses 1a and 1b). Second (step 2), we mapped the temporal relationship between timeand strain-based work-home interference on one hand and fatigue and depressive complaints on the other, using structural equation modeling (43). The model included four dependent (endogenous) variables, that is, the four core variables (time-based work-home interference, strain-based work-home interference, fatigue, and depressive complaints) measured at time 2. The time-1 measures of these four variables served as independent (exogenous) variables, together with the four covariates (ie, time-1 workload, time-1 job control, age, and gender).

Four models were tested against each other. Model 1 (M1), the no causation model, included only lagged effects from the time-1 measure of each core variable on the time- 2 measure of the same variable. Thus this model assumed that time- and strain-based work-home interference and both health indicators do not affect each other temporally. Model 2 (M2), the normal causal model, corresponding with hypothesis 1a, was identical to M1 but included additional effects of time- and strainbased work-home interference (time 1) on fatigue and depressive complaints (time 2). Note that health status at time 1 is controlled for (as M2 is an extension of M1 that already included lagged effects from each health indicator at time 1 on the same health indicator at time 2). Model 3 (M3), the reversed causal model, corresponding with hypothesis $1 \mathrm{~b}$, was also identical to M1 but included additional effects of fatigue and depressive complaints (time 1) on both types of work-home interference (time 2). Note here that work-home interference at time 1 was controlled (as M3 was an extension of M1 that already included lagged effects from work-home interference at time 1 on work-home interference at time 2). Finally, model 4 (M4), the reciprocal model, integrates all three previous models, including cross-lagged reciprocal effects (i) from fatigue and depressive complaints (time 1) on (time- and strain-based) work-home interference (time 2) and (ii) from (time- and strainbased) work-home interference (time 1) on fatigue and depressive complaints (time 2 ). This model corresponded with both hypothesis $1 \mathrm{a}$ and hypothesis $1 \mathrm{~b}$, since it was assumed that (time- and strain-based) work-home interference can result in increased levels of health complaints 1 year later, as well as the other way around (health complaints can result in increased levels of work-home interference 1 year later).
The fit of these four models in step 2, as well as of the four models in step 1 (the preliminary analyses), were compared using the standard chi-square test, and Bentler's (44) non-normed fit index (NNFI), the adjusted goodness-of-fit index (GFI), the root mean square error of approximation (RMSEA), and the comparative fit index (CFI) (45). Values of $\geq 0.90$ (NNFI, AGFI and CFI) and $\leq 0.08$ (RMSEA) indicated an acceptable fit (46).

Subgroup analysis (hypotheses 2 to 6). In a final step (step 3), we examined the relationship between stable and changed levels of time- and strain-based workhome interference and the development of health complaints over time. Therefore, four subgroups with different patterns of time- and strain-based work-home interference across time were created using the mediansplit method. For each type of work-home interference, those who scored above the median in both phases were assigned to the "stable high" group, whereas those who scored below the median on both occasions formed the "stable low" group. Incumbents of the change-from-lowto-high group had work-home interference scores below the median at time 1 and above the median at time 2. Incumbents of the change-from-high-to-low group had work-home interference scores above the median at time 1 and below the median at time 2 .

To examine the course of the health complaints for the four work-home interference subgroups, we conducted three types of analyses of variance. At first, a 4 (group: the four work-home interference subgroups) $\times$ 2 (time: time 1 versus time 2 ) $\times 2$ (health: fatigue and depressive complaints) multiple analysis of variance (MANCOVA) was executed, with time and health as within-participant factors. Workload (time 1), job control (time 1), gender, and age were included as covariates. Second, a series of analyses of variance (ANOVA) (with each health indicator in each phase as a dependent variable and the four work-home interference subgroups as factors) were conducted to map differences among the subgroups in each phase. Post-hoc tests were conducted to test which groups differed significantly from each other (hypotheses 2 and 4). Additional t-tests were conducted within each work-home interference subgroup to determine whether the level of health complaints changed across time within each subgroup (hypotheses 3, 5, and 6).

The fact that work-home interference levels may have alternated over time for some of the participants does not yet explain why such changes took place. Therefore, some additional analyses were conducted to address this question. It is plausible that changes in the work-home interference levels were related to reported job or family changes (ie, changes in job type, in police force, or in objective family conditions) or to changes 
in reported work characteristics (eg, changes in workload or job control); changes in reported family characteristics, such as changed domestic or care-giving responsibilities, were not measured in our study. Concerning the reported job or family changes, chi-square tests were conducted to reveal whether or not the change (high to low and low to high) work-home interference subgroups included a larger proportion of workers who reported a change in job type, police force, or objective family circumstances than the stable (high and low) groups. To determine whether the two change groups reported more alterations in reported workload or job control across time than both stable groups, a 4 (group: the four work-home interference groups) $\times 2$ (time: time 1 versus time 2 ) $\times 2$ (work characteristics: workload and job control) MANOVA was conducted.

\section{Results}

\section{Preliminary analyses}

Four models for the associations among the items of the four core variables were tested and compared for each phase. Our analyses revealed that only the model in which four latent factors were created for time-based work-home interference, strain-based work-home interference, fatigue, and depressive complaints fit the data well (time $1: \chi_{(183,706)}=539.97, \mathrm{NNFI}=0.89, \mathrm{GFI}=0.93$,

Table 2. Fit indices of five alternative models for the causal relations between the (time- and strain-based) work-home inteference and health complaints (ie, fatigue and depressive complaints). [NNFI = nonnormed fit index; $A G F I=$ adjusted goodness-of-fit index; RMSEA = root mean square error of approximation; $\mathrm{CFI}=$ comparative fit index; $\mathrm{M}^{\mathrm{a}}=$ includes only lagged effects; $M 2^{b}=$ identical to $M 1$, but extended with normal causal relationships; $\mathrm{M}^{\mathrm{C}}{ }^{\mathrm{C}}=$ identical to $\mathrm{M} 1$, but extended with reversed causal relationships; M4 = integrates models M1, M2 and M3 (ie, lagged effects, normal and reversed causal relationships); M5 = identical to $\mathrm{M} 2$, but with nonsignificant paths being constrained to zero]

\begin{tabular}{lrrrrrr}
\hline Model & $\chi^{2}$ & df & NNFI & AGFI & RMSEA & CFI \\
\hline M1 (no causation model) & 46.01 & 12 & 0.91 & 0.93 & 0.063 & 0.98 \\
M2 (normal causal model) & 17.89 & 8 & 0.96 & 0.96 & 0.042 & 1.00 \\
M3 (reversed causal model) & 42.30 & 8 & 0.87 & 0.90 & 0.077 & 0.98 \\
M4 (reciprocal model) & 15.47 & 4 & 0.91 & 0.93 & 0.064 & 0.99 \\
M5 (final model) & 24.04 & 20 & 0.99 & 0.98 & 0.017 & 1.00 \\
\hline
\end{tabular}

a Measure (time 1) $\rightarrow$ same measure (time 2).

b Work-home interference (time 1) $\rightarrow$ health complaints (time 2).

c Health complaints (time 1) $\rightarrow$ work-home interference (time 2).
RMSEA $=0.054$, and CFI $=0.90 ;$ time $2: \chi_{(183,706)}=$ 575.73, NNFI $=0.91$, GFI $0=0.93$, RM-SEA $=0.057$, and CFI =0.92). The three other models (assuming one, two, and three latent factors, respectively) did not show an acceptable fit (all NNFI, GFI, CFI <0.90, all RMSEA >0.08). ${ }^{3}$ Thus the four core variables in our study can be regarded as empirically distinct, although related (table 1, page 20), constructs.

Concerning the possible differences in relationships among these core variables for the workers who reported no change in their work or family situation (i) versus those who reported a change in their work situation (ii), in their family situation (iii), or in both domains (iv), the LISREL analysis showed that the model in which the covariance matrices were set equal showed an acceptable fit $\left(\chi_{(234)}^{2}=342.49\right.$, RMSEA $=0.03$, NNFI $=$ 0.95 and $\mathrm{CFI}=10.95)$. Thus the relationships among the core variables were equal for the four groups and were not affected by changes that may have occurred in job type, police force, or objective family circumstances.

\section{Causal relations}

Table 2 presents the fit of the four alternative models (no causation, normal causal, reversed causal, and reciprocal) to map the temporal relationships between both types of work-home interference and both health indicators.

All the models fit the data reasonably well. A closer inspection of the fit indices revealed that model 2 [M2: normal causal model assuming that (time- and strainbased) work-home interference (time 1) was related to increased levels of fatigue and depressive complaints (time 2)] fit the data significantly better than model 1 [M1: no causation model, change in $\chi^{2}(\mathrm{M} 2-\mathrm{M} 1)=28.1$ with 4 df, $\mathrm{P}<0.001$ ]. Model 3 [M3: reversed causal model assuming that health complaints (time 1) are associated with increased (time- and strain-based) work-home interference (time 2)], on the other hand, did not provide a better fit than M1 [change in $\chi^{2}(\mathrm{M} 3-\mathrm{M} 1)=3.71$ with $4 \mathrm{df},>0.05]$. Also model 4 [M4: reciprocal model assuming cross-lagged reciprocal relationships between (time- and strain-based) work-home interference and both health indicators] fit the data slightly better than model 1 [change in $\chi^{2}(\mathrm{M} 4-\mathrm{M} 1)=25.1$ with $8 \mathrm{df}$, $\mathrm{P}<0.001$ ] and model 3 [change in $\chi^{2}(\mathrm{M} 4-\mathrm{M} 3)=26.83$ with 4 df, $\mathrm{P}<0.001]$. Although model 2 and model 4 fit the data about equally well, the crucial reversed causal relationships [from fatigue and depressive complaints (time 1) to increased levels of (time- and strain-based) work-home interference (time 2)] specified in model 4, presented here, but is available from the first author upon request. 
were not significant. As model 4 was less parsimonious (4 df), model 2 ( $8 \mathrm{df}$ ) was accepted as the best fitting model $\left(\chi_{(8,698)}^{2}=17.89, \mathrm{NNFI}=0.96\right.$, AGFI $=0.96$, RMSEA $=0.042$, CFI $=1.00)$.

Not all the paths in model 2 were statistically significant. Most importantly, the relationships of timebased work-home interference (time 1) and both health indicators 1 year later were not significant, and, therefore, increases in health complaints could not be predicted from time-based work-home interference 1 year earlier. After omitting these and other (less relevant) nonsignificant paths in a stepwise fashion, the fit of the final model (M5) remained acceptable $\left(\chi_{(20,698)}^{2}=24.04\right.$, $\mathrm{NNFI}=0.99, \mathrm{AGFI}=0.98, \mathrm{RMSEA}=0.017, \mathrm{CFI}=$ 1.00). This model is presented in figure 1.

In summary, the results provide support for hypothesis 1a, but only for strain-based work-home interference. Higher levels of strain-based work-home interference at time 1 are associated with increased levels of fatigue $(\beta=0.16, \mathrm{P}<0.001)$ and depressive complaints $(\beta=0.15, \mathrm{P}<0.001) 1$ year later $[$ after control for gender, age, fatigue (time 1), depressive complaints (time 1), workload (time 1) and job control (time 1)]. In addition (not shown in figure 1), some covariates were related to the core variables at time 1 (see table 1 ). Concerning the relationships between the covariates and the core variables at time 2 (see figure 1), workload (time 1) was positively related to time- and strain-based workhome interference $(\beta=0.15$ and $\beta=0.09$, respectively) and fatigue $(\beta=0.09)$, job control was not related with the core variables at time 2 , females reported slightly higher levels of fatigue and depressive complaints than males ( $\beta=0.11$ and $\beta=0.10$, respectively), and age was negatively (though weakly) associated with time-based work-home interference $(\beta=-0.07)$. Finally, the acrosstime correlations of the core variables were rather high, the levels of (time- and strain-based) work-home interference at time 2 being relatively strongly predicted by the levels of these measures at time $1\left(\beta_{\text {time-based }}=0.56\right.$ and $\left.\beta_{\text {strain-based }}=0.57\right)$, and this was also true, though to a less extent, for the two health indicators $\left(\beta_{\text {fatigue }}=0.36\right.$ and $\beta_{\text {depressive complaints }}=0.33$ ).

\section{Subgroup analysis}

In step 3, we examined the course of health complaints in each work-home interference subgroup. For this purpose, we created four subgroups using the scores on strain-based work-home interference only [time-based work-home interference maintained no temporal relationship with each of the two health indicators (step 2)]. Table 3 presents the number of incumbents in each work-home interference subgroup, as well as the means and standard deviations for each health indicator with respect to each work-home interference subgroup in each phase. For each work-home interference subgroup, the t-values indicate whether the observed change in health complaints between time 1 and time 2 was significant.

The results of the MANCOVA showed no significant main effect of time $[F(2,674)=0.61$, not significant] and, therefore, indicated that, for the whole sample (disregarding the work-home interference subgroups), the level of health complaints did not differ significantly between the two phases. A significant main effect of group did exist $[\mathrm{F}(6,1350)=28.39, \mathrm{P}<0.001]$ for both fatigue $[\mathrm{F}(3,675)=53.72, \mathrm{P}<0.001]$ and depressive complaints $[\mathrm{F}(3,675)=22.18, \mathrm{P}<0.001]$. This finding indicates that the four work-home interference subgroups differed in their levels of fatigue and depressive complaints (irrespective of the development of these complaints over time). Finally, the MANCOVA revealed a significant group-by-time interaction $[\mathrm{F}(6,1350)=9.27, \mathrm{P}<0.001]$ for both fatigue $[\mathrm{F}(3)=18.24, \mathrm{P}<0.001]$ and depressive complaints $[\mathrm{F}(3)=4.09, \mathrm{P}<0.001]$, and, therefore, pointed to the fact that the four work-home interference subgroups differed with respect to their health course

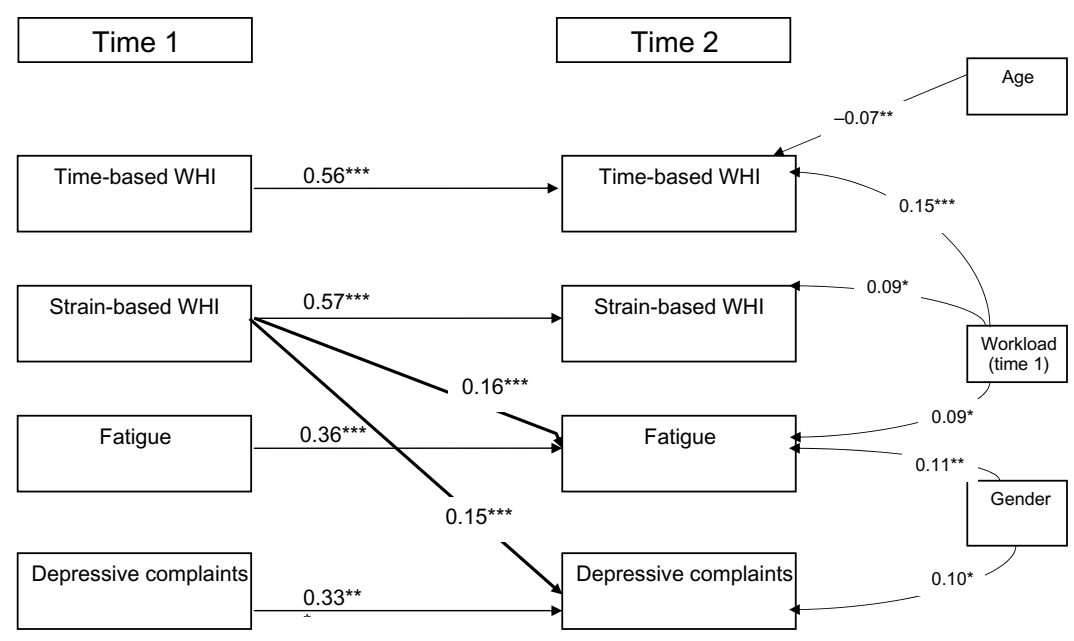

Figure 1. The final model (M5). ${ }^{* *} \mathrm{P}<0.01$, ${ }^{* \star *} P<0.001(\mathrm{WHI}=$ work-health interference) 
Table 3. Means and standard deviations of each health indicator for each phase of the study and for each work-home interference subgroup.

\begin{tabular}{|c|c|c|c|c|c|c|c|c|c|c|c|}
\hline \multirow[t]{3}{*}{ Subgroup } & \multirow[t]{3}{*}{ N } & \multicolumn{5}{|c|}{ Fatigue } & \multicolumn{5}{|c|}{ Depressive complaints } \\
\hline & & \multicolumn{2}{|c|}{ Time 1} & \multicolumn{3}{|c|}{ Time 2} & \multicolumn{2}{|c|}{ Time 1} & \multicolumn{3}{|c|}{ Time 2} \\
\hline & & Mean & SD & Mean & SD & $\mathrm{t}$-value & Mean & SD & Mean & SD & $\mathrm{t}$-value \\
\hline Stable low & 357 & 0.89 & 0.53 & 0.88 & 0.60 & -0.39 & 1.12 & 0.21 & 1.13 & 0.24 & 0.92 \\
\hline Change from high to low & 63 & 1.24 & 0.54 & 1.14 & 0.63 & -1.14 & 1.30 & 0.40 & 1.27 & 0.35 & 0.81 \\
\hline Change from low to high & 104 & 1.12 & 0.50 & 1.61 & 0.85 & $5.58^{\mathrm{a}}$ & 1.18 & 0.30 & 1.27 & 0.32 & $2.71^{\mathrm{a}}$ \\
\hline Stable high & 204 & 1.35 & 0.50 & 1.59 & 0.73 & $4.60^{b}$ & 1.25 & 0.26 & 1.30 & 0.29 & $2.50^{a}$ \\
\hline
\end{tabular}

a $P<0.01$.

b $P<0.05$.

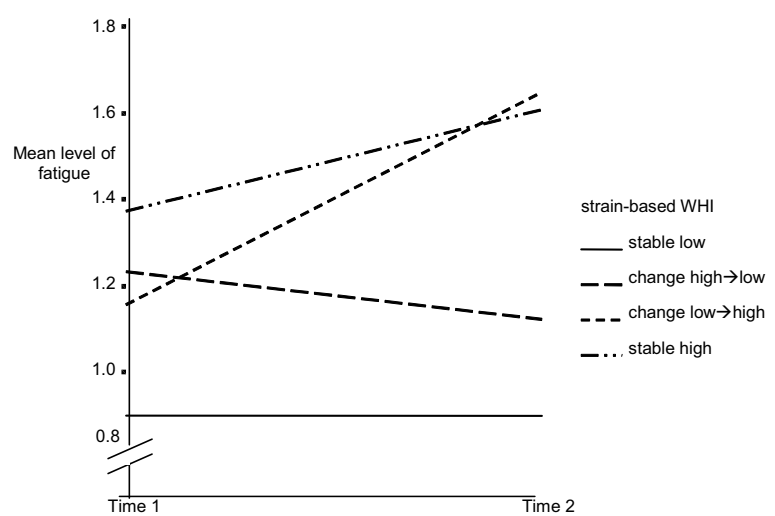

Figure 2. Development of fatigue over time in each work-home interference subgroup. (WHI = work-home interference)

across time. Graphic representations of these differences are shown for fatigue and depressive complaints in figures 2 and 3.

The follow-up ANOVA revealed that the four workhome interference subgroups differed in their levels of health complaints at both time 1 [fatigue: $\mathrm{F}(3,724)=$ 43.65, $\mathrm{P}<0.001$; depressive complaints: $\mathrm{F}(3,704)=7.48$, $\mathrm{P}<0.001$ ] and time 2 [fatigue: $\mathrm{F}(3,723)=42.49, \mathrm{P}<0.001$; depressive complaints: $\mathrm{F}(3,706)=12.88, \mathrm{P}<0.001]$. Posthoc tests were conducted to examine these differences in more detail.

Differences among the subgroups in each phase. At time 1 , the stable high group reported significantly higher levels of fatigue and depressive complaints than the stable low group (time 1: change in mean score $=0.46$, $\mathrm{P}<0.01$ for fatigue, change in mean score $=0.13, \mathrm{P}<0.01$ for depressive complaints) and significantly higher levels of fatigue than the change-from-low-to-high group (time 1: change in mean score $=0.23, \mathrm{P}<0.01$ ). At time 2 , the stable high group reported a significantly higher level of fatigue than the stable low group (time 2: change in mean score $=0.71, \mathrm{P}<0.01)$ and the change-fromhigh-to-low group (time 2: change in mean score $=0.45$, $\mathrm{P}<0.01)$. In addition, the stable high group reported significantly more depressive complaints than the

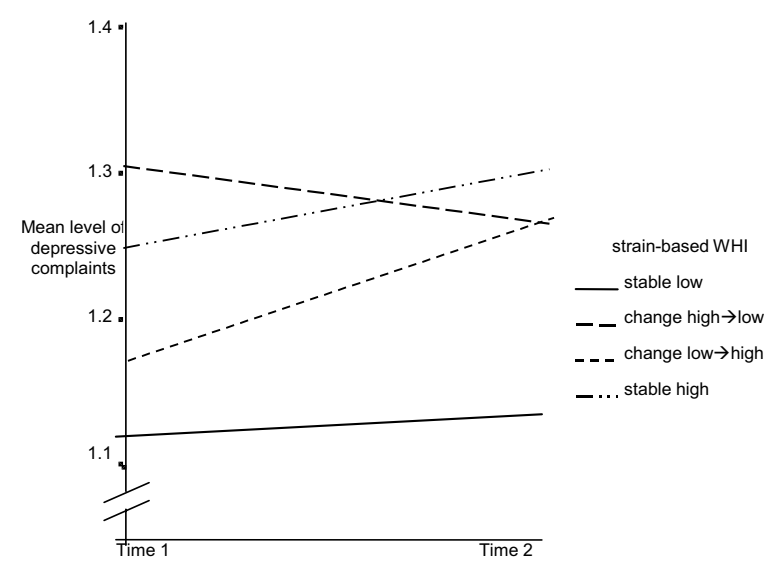

Figure 3. Development of depressive complaints over time for each work-home interference subgroup. (WHI = work-home interference)

stable low group (time 2: change in mean score $=0.17$, $\mathrm{P}<0.01$ ). In general, these results support hypothesis 2 , stating that those who experienced higher levels of work-home interference in both phases of the study (stable high group) would experience more health complaints than those who reported relatively low levels of work-home interference at the respective measurement points.

Support was also found for hypothesis 4, predicting that those who experienced low levels of work-home interference in both phases (stable low group) experienced fewer health complaints than those who reported relatively high levels of work-home interference at the respective measurement points. In fact, as was already shown, the stable low group reported fewer health complaints than the stable high group in both phases. In addition, this group reported lower levels of fatigue than the change-from-high-to-low group (time 1: change in mean score $=0.35, \mathrm{P}<0.01 ;$ time 2 : change in mean score $=0.27, \mathrm{P}<0.05)$ and the change-from-low-to-high group (time 1: change in mean score $=0.23, \mathrm{P}<0.01$; time 2: change in mean score $=0.73, \mathrm{P}<0.01$ ) in both phases. As to depressive complaints, the stable low group reported fewer complaints than the change-fromhigh-to-low group in both phases (time 1: change in mean score $=0.18, \mathrm{P}<0.01$; time 2 : change in mean 
score $=0.13, \mathrm{P}<0.01)$ and the change-from-low-to-high group at time 2 (change in mean score $=0.14, \mathrm{P}<0.01$ ).

\section{Development of fatigue and depressive complaints across} time. In order to map the development of health complaints within each work-home interference subgroup, t-tests were performed for each subgroup to determine whether the time- 1 and time- 2 scores differed significantly (table 3 ). Within the stable high group, the levels of both fatigue $(t=4.60, \mathrm{P}<0.01)$ and depressive complaints $(t=2.50, \mathrm{P}<0.05)$ appeared to increase significantly over the 1 -year period. This finding supports hypothesis 3 and argues that health would deteriorate during the observation period for this group of workers. In the stable low group, the health status remained stable during the 1-year period. In accordance with hypothesis 5, a significant increase in the levels of both fatigue $(t=5.58, \mathrm{P}<0.01)$ and depressive complaints $(t=2.71$, $\mathrm{P}<0.01)$ across time was observed in the change-fromlow-to-high group. Finally, and in disagreement with our expectations, no significant decrease in health complaints was observed in the change-from-high-to-low group (hypothesis 6 not supported).

With respect to the possible causes of changed levels of work-home interference over time, none were related to reported changes in job type, police force, or family circumstances, as measured in this study (none of the chi-square values were significant). However, with respect to changes in reported workload and job control, the MANOVA revealed a significant group $\times$ time interaction $[\mathrm{F}(6,1422)=4.19, \mathrm{P}<0.01]$ for both work characteristics $[\mathrm{F}(3,711)=6.46, \mathrm{P}<0.01$, and $\mathrm{F}(3,711)=2.68, \mathrm{P}<0.05$, respectively]. Additional $\mathrm{t}-$ tests revealed that the incumbents of the change-fromhigh-to-low group reported, in contrast with the other work-home interference subgroups, favorable changes in work characteristics across time, namely, a decrease in workload $[\mathrm{T}(61)=2.3, \mathrm{P}<0.05]$ and an increase in job control $[\mathrm{T}(62)=2.62, \mathrm{P}<0.05]$. Similar changes in an unfavorable direction were not found, however, for the change-from-low-to-high group.

\section{Discussion}

In our study, we examined the temporal relationships between time- and strain-based work-home interference and two health indicators (fatigue and depressive complaints) from the perspective of the effort-recovery model. The goal was twofold. First, we addressed the question of causality in the relationship between (time- and strain-based) work-home interference and health. Second, we were interested in how health developed in theoretically derived subgroups that differed in their starting point and development of work-home interference across time.

\section{Causality in the relationship between work-home interference and health}

We examined the hypothesis that time- and strain-based work-home interference predict health deterioration 1 year later ("normal causation"), as well as an alternative (but not per se competing) hypothesis that health complaints act as precursors of increased levels of (timeand strain-based) work-home interference 1 year later ("reversed causation") $(7,47)$. The results provided support for a temporal relationship between strain-based work-home interference and increased levels of fatigue and depressive complaints 1 year later (hypothesis 1a supported). No support was found, however, for a reversed causal relationship between prior health complaints and increased levels of work-home interference (hypothesis $1 \mathrm{~b}$ not supported). Whereas the conclusion that strain-based work-home interference is likely to act as a precursor of health deterioration seems to be justified, the conclusion that reversed causation would not exist, is not that straightforward. We should note here that, due to the exclusion of workers with (very) high levels of burnout in the first phase, our sample incorporated relatively healthy workers (ie, the healthy worker effect). As a consequence, the relatively low levels of fatigue and depressive complaints reported in the first phase were possibly less powerful in predicting changes in work-home interference across time than they would have been when no such health-based selection had been made.

Although the causal relationships of strain-based work-home interference with fatigue $(\beta=0.16)$ and depressive complaints $(\beta=0.15)$ did not seem very strong at first sight, we must realize that a substantial proportion of the variance in each health indicator was already accounted for by the same indicator measured 1 year earlier. In fact, the high across-time correlations of fatigue (0.47) and depressive complaints (0.40) indicate that these levels of complaints were rather stable. As a consequence, the proportion of variance left to be explained that may be linked to change in the levels of health complaints was only small. Furthermore, also in studies that examined the causal relationships between stressors and strain, the betas reported were, on the average, only 0.12 (18). In this light, the relevance of the causal associations found in our study should not be underestimated (48).

Although a causal relationship was found for strainbased work-home interference and health, a similar result for time-based work-home interference was lacking. One explanation is that time-based work-home 
interference may be better manageable than strain-based work-home interference. For instance, one can (within certain limits) decide to manage workhours better, to reduce or avoid working overtime, and to discuss with one's spouse what time investment at home can reasonably be expected. It seems more difficult, though, to cope with feelings of work-related tension that carry over to the home domain (ie, strain-based work-home interference). A second explanation is that this workrelated tension impeding functioning and recovery at home (ie, strain-based work-home interference) acts as a more immediate precursor of increased levels of fatigue and depressive complaints than time-based workhome interference. To put it differently, time- and strainbased work-home interference may not occur at the same stage in the causal process resulting in health impairment, but may very well occur at different stages in this causal chain.

\section{Health course in subgroups with different starting points and patterns for work-home interference}

The results of our study matched our hypotheses 2 to 6 remarkably well. An increase in strain-based workhome interference (change-from-low-to-high group) was associated with an increase in health complaints across time (hypothesis 5 supported). More interestingly, the workers who experienced a relatively high level of work-home interference in both phases of the study (stable high group) not only reported more health complaints than those who reported a low work-home interference level in the respective phase (hypothesis 2 supported), but also showed a deterioration in health over time (hypothesis 3 supported). This latter finding is in line with the effort-recovery model and therefore suggests that the persistence of a relatively high level of work-home interference (and related lack of recovery) is accountable for an accumulation of health complaints. Alternatively, a decrease in strain-based workhome interference (change-from-high-to-low group) did not result in an accompanying significant decrease in health complaints (hypothesis 6 not supported). Possible explanations may be that the 1-year time lag was too short for health complaints to diminish or that unknown factors (unmeasured third variables) in the work or home domain may have preserved a high level of health complaints, independently of a decreased level of work-home interference. Finally, and as expected, those who experienced low strain-based work-home interference in both phases of the study (stable low group) experienced fewer health complaints than workers who reported a high level of work-home interference in the respective phase (hypothesis 4 supported) and showed no health changes over time.
With respect to the causes of changed levels of strain-based work-home interference across time, none of the variables measured in our study were able to offer a full explanation. The reported changes in job type, police force, or objective family circumstances did not explain the changes in work-home interference since the workers who showed a (favorable or unfavorable) change in work-home interference did not report such environmental changes more often than did those who showed a stable (high or low) level of work-home interference. However, changes in reported job characteristics did help us - at least partly-to understand what may have caused changes in work-home interference. A decrease in work-home interference turned out to be associated with favorable changes in workload and job control. However, an increase in work-home interference could not be explained in a similar way by unfavorable changes in these job characteristics and, therefore, implied that these work-home interference changes were probably related to other (unmeasured) variables in the work or home domain.

\section{Strengths and limitations}

We believe that our study contributes to previous research in the area of work-home interference, both theoretically and methodologically. First, and in contrast with the abundance of cross-sectional studies in this field, we provided evidence for a causal relationship of strain-based work-home interference and health impairment (ie, increased levels of fatigue and depressive complaints) 1 year later. Second, whereas most studies solely explore normal causal relationships (ie, work-home interference acts as a precursor of health impairment), in our study also reversed causal relationships (ie, health complaints act as precursors of increased work-home interference), as well as reciprocal relationships (ie, work-home interference and health affect each other mutually across time), were carefully tested, whereby potential third variables that may cause spurious relations between work-home interference and health were controlled (eg, workhours, workload, and job control). Our results did not provide support for a reversed causal relationship between work-home interference and employee health. Third, we studied the relationship between work-home interference and employee health from an original and relevant theoretical perspective (ie, the effort-recovery model) that provided insight as to why high levels of work-home interference would result in health impairment. Fourth, our study is one of the first in the field of research on work-home interference [see the report by Kinunnen et al (8) for a notable exception] that acknowledged the fact that workers have different starting points and courses of work-home interference across time. By creating subgroups with 
different work-home interference patterns, we were able to demonstrate that (favorable or unfavorable) changes in work-home interference across time were accompanied by (favorable or unfavorable) changes in health status, and, more importantly, that a long-lasting experience of high work-home interference resulted in an accumulation of health complaints.

Although our study addressed several important shortcomings in previous research, it still has some limitations of its own. First, it relied exclusively on selfreport measures, which may have resulted in an overestimation of the statistical associations found due to common method variance. However, this possibility cannot explain why some relationships were found to be statistically significant, whereas others were not. Moreover, as Semmer et al (49) have recently argued, alternative measures (eg, observational or physiological measures) will not provide more reliable estimates of the relationships studied, as they are not free of error variance as well, and should therefore not be considered superior substitutes for self-report measures. Besides, we have reason to believe that the statistical associations found by us may have been underestimations (rather than overestimations) of the true relationships between work-home interference and employee health, and this assumption refers to our second and third point of concern.

As was already discussed earlier in this section, participants who reported a (very) high burnout level in the first phase were excluded from the follow-up study. Although there were good reasons to do so from the perspective of burnout etiology, it is plausible that, due to this health-based selection and a related restriction of range in the core variables under study (and particularly in the health indicators), associations among these variables were underestimations of the true associations, or did not reach significance at all (eg, the reversed causal relationships).

Another concern is that the 1-year time lag used in the current study may not have been appropriate for detecting substantial effects of work-home interference on health impairment. In general, there is hardly any consensus about what time lag is appropriate for studying the effects of, for example, work characteristics on employee health (9) and, consequently, there is a wide variation in the time lags chosen. A recent review of 45 longitudinal studies (50) that addressed the relationships between work characteristics and psychological health revealed that in high-quality studies (eg, with a full panel design and a theory-guided choice for a time lag) the most consistent effects were demonstrated over a 1-year period. Although the time lag chosen by us congrues with this evidence, we cannot exclude the possibility that this particular time lag deviated from the underlying causal interval and that the statistical associations found in our study were, thus, underestimations of the true strength of the causal relationships (29).

A final limitation is that we were unable to provide a satisfactory explanation for why subgroups of workers experienced changes in work-home interference during the observation period (only a favorable change in job characteristics could partly explain a decrease in work-home interference). It may be that changes responsible for changed work-home interference levels did occur in the work or family domain, but were not measured (or not sensitively enough). In fact, the changes that we addressed were rather radical life events (eg, marriage, divorce, birth of a child, transfer to another job or force). Moreover, whereas some more subtle changes in the work domain were detected (eg, changed levels of workload and job control), other changes in this domain (eg, changes in quality of relationships at work or in career perspectives), as well as more subtle changes in the home domain (eg, changed participation in domestic activities or in other nonwork activities, such as volunteer aid or courses) were not addressed.

\section{Future directions and practical implications}

Considering these limitations, our study provides some directions for future research. At first, future research should explore different time lags in order to determine what time interval is appropriate for detecting the effects of work-home interference on employee health ( 9 , $50)$. One could also include additional indicators of health and well-being in order to determine the appropriate time lag for different health indicators. As results of previous longitudinal research in this area (8) also suggest that the effects of work-home interference on health may be observed for men and women in different periods of time, a related recommendation is to address possible gender differences when time lags of different lengths are explored. Another unresolved issue is if and where time-based work-home interference fits in the causal chain. We have suggested that time-based work-home interference may be a more distant antecedent of health when compared with strain-based workhome interference. In most studies, including our own, both types of work-home interference are positioned equally in the stressor-stress-strain relationships, whereas it is possible that the two types of work-home interference occur at different stages in the causal process. Longitudinal studies (preferably employing more than two phases) including the two types of work-home interference, as well as various health indicators, may further disentangle the possible causal relationships. A final recommendation is to include, in addition to workload and job control, also other job characteristics (eg, quality of relationships at work), as well as relevant home characteristics (eg, domestic obligations) that may 
provide insight as to why some workers experience alterations in work-home interference levels and others do not. We follow Geurts \& Demerouti (2) in their suggestion "to assess the home situation with high and the same preciseness as the work place is assessed [p 306]".

From a practical point of view, our study identified (strain-based) work-home interference as a serious risk for the occurrence and increase of fatigue and depressive complaints. Such health impairment is obviously undesirable from an employee perspective, but also from an organizational perspective, as relationships with sickness and absenteeism have been well established. For example, in recent studies, it has been shown that a high level of fatigue results in an increased incidence of infections (51) and that a high need for recovery after work, indicative of the spillover of strain built up at work (ie, strain-based work-home interference ), is linked to increased risks of sickness absence (52). The linkages of (strain-based) work-home interference and experienced fatigue with manifest problems such as infection, diseases, and sickness absence stress the importance of a company policy emphasizing the prevention of work-home interference. In order to promote balance and to prevent interference between work and private life, companies should provide work-family facilities that enable employees to better align both life spheres, for instance, by offering flexible worktime alternatives (eg, part-time jobs, compressed work schedules, and flexible start and finishing times), and dependent care facilities [eg, (subsidized) parental leave and (subsidized) child care facilities] $(53,54)$. In addition, companies should create a company culture in which employees who experience work-home interference feel entitled to use the facilities that are available (2). We hope that our study will encourage companies to develop a supportive work-family policy and culture and that researchers will be inspired to further disentangle the temporal relationships between work-home interference and health.

\section{Acknowledgments}

This study was supported by ASPASIA grant 015.000.027 from the Netherlands Organization for Scientific Research (NWO).

We also thank the employers and employees of the Dutch police force for their participation in this study.

\section{References}

1. Frone MR. Work family balance. In: Quick JC, Tetrick LE, editors. Handbook of occupational health psychology. Wash- ington (DC): American Psychological Association; 2003. p 143-62.

2 Geurts S, Demerouti E. Work-nonwork interface: a review of theories and findings. In: Schabracq MJ, Winnubst JAM, Cooper CL, editors. The handbook of work and health psychology. Chichester (US): John Wiley \& Sons Ltd; 2003.

3. Greenhaus JH, Beutell NJ. Sources of conflict between work and family roles. Acad Manage Rev 1985;10:76-88.

4. Allen TD, Herst DEL, Bruck, CS, Sutton M. Consequences associated with work-to-family conflict: a review and agenda for future research. J Occup Health Psychol 2000;5:278-308.

5. Frone MR, Russell M, Cooper ML. Relation of work-family conflict to health outcomes: a four-year longitudinal study of employed parents. J Occup Organ Psychol 1997;70:325-35.

6. Grant-Vallone EJ, Donaldson SI. Consequences of work-family conflict on employee well-being over time. Work Stress 2001;15:214-26.

7. Kelloway EK, Gottlieb BH, Barham L. The source, nature, and direction of work and family conflict: a longitudinal investigation. J Occup Health Psychol 1999;4:337-46.

8. Kinunnen U, Geurts S, Mauno S. Work-to-family conflict and its relationship with well-being: a one year longitudinal study. J Vocat Behav 2004;18(1):1-23.

9. Taris TW, Kompier M. Challenges in longitudinal designs in occupational health psychology [editorial]. Scand J Work Environ Health 2003;29(1):1-4.

10. Geurts S, Kompier MAJ, Roxburgh S, Houtman ILD. Does work-home interference mediate the relationship between workload and well-being? J Vocat Behav 2003;63:532-59.

11. Kahn RL, Wolfe DM, Quinn RP, Snoek JD, Rosenthal RA. Organizational stress: studies in role conflict and ambiguity. New York (NY): John Wiley; 1964.

12. Frone MR, Russell M, Cooper ML. Antecedents and outcomes of work-family conflict: testing a model of the workfamily interface. J Appl Psychol 1992;77:65-78.

13. Kinnunen U, Mauno S. Antecedents and outcomes of workfamily conflict among employed women and men in Finland. Hum Rel 1998;51:157-77.

14. Frone MR, Yardley JK, Markel KS. Developing and testing an integrative model of the work-family interface. J Vocat Behav 1997;50:145-67.

15. Burke RJ. Some antecedents and consequences of work-family conflict. J Soc Behav Pers 1988;3:287-302.

16. Grandey AA, Cropanzano R. The conservation of resources model applied to work-family conflict and strain. J Vocat Behav 1999;54:350-70.

17. Demerouti E, Bakker AB, Bulters AJ. The loss spiral of work pressure, work-home interference and exhaustion: reciprocal relations in a three wave study. J Vocat Behav 2004;64:13149.

18. Dormann C, Zapf D. Social stressors at work, irritation, and depressive symptoms: accounting for unmeasured third variables in a multi-wave study. J Occup Organ Psychol 2002; 75:33-58.

19. Kasl SV, Jones BA. An epidemiological perspective on research design, measurement, and surveillance strategies. In: Quick JC, Tetrick LE, editors. Handbook of occupational health psychology. Washington (DC): American Psychological Association; 2003. p 379-98.

20. de Lange AH, Taris TW, Kompier MAJ, Houtman, ILD, Bongers PM. Effects of stable and changing demand-control histories on worker health. Scand J Work Environ Health 2002;28(2):94-108.

21. Meijman TF, Mulder G. Psychological aspects of workload. 
In: Drenth PJD, Thierry H, de Wolff CJ, editors. Handbook of work and organizational psychology. 2nd ed. Hove (UK): Psychology Press/Erlbaum (UK) Taylor \& Francis; 1998. p 533.

22. Hobfoll SE. Conservation of resources: a new attempt at conceptualizing stress. Am Psychol 1989;44:513-24.

23. Ursin H. Personality, activation and somatic health: a new psychosomatic theory. In: Levine S, Ursin H, editors. Coping and Health. New York (NY): Plenum Press; 1980. p 259-79.

24. Sonnentag S. Work, recovery activities, and individual wellbeing: a diary study. J Occup Health Psychol 2001;6(3):196210.

25. Kompier M. Arbeid en gezondheid van stadsbuschauffeurs [Work and health among city bus drivers]. Delft (The Netherlands): Eburon; 1988.

26. Sluiter JK, Van der Beek AJ, Frings-Dresen MHW. The influence of work characteristics on the need for recovery and experienced health: a study on coach drivers. Ergonomics 1999;42:573-83.

27. Maslach C, Jackson SE. Burnout in organizational settings. Appl Soc Psychol Ann 1984;5:133-53.

28. Schaufeli W, Van Dierendonck D. Utrechtse Burnout Schaal: Handleiding [Utrecht burnout scale: manual]. Lisse (The Netherlands): Swets \& Zeitlinger; 2000.

29. Taris TW. A primer in longitudinal data analysis. London (UK): Sage publications; 2000.

30. Grzywacs JG, Marks NF. Reconceptualizing the work-family interface: an ecological perspective on the correlates of positive and negative spillover between work and family. J Occup Health Psychol 2000;5:111-26.

31. Van der Hulst M, Geurts S. Associations between overtime and psychological health in high and low reward jobs. Work Stress 2001;15:227-40.

32. Bakker AB, Geurts SAE. Towards a dual-process model of work-home interference. Work Occup 2004;31(3):345-66.

33. Demerouti E, Geurts S, Bakker A, Euwema M. The impact of shiftwork on work-home conflict, job attitudes and health. Ergonomics 2004;47(9):987-1002.

34. Kohout FJ, Berkman LF, Evans DA, Cornoni-Huntley J. Two shorter forms of the CES-D Depression Symptoms Index. J Aging Health 1995; 5:179-93.

35. Radloff LS. The CES-D Scale: a self-report depression scale for research in the general population. Appl Psychol Meas 1977;1:385-401.

36. Dhondt S, Houtman ILD. NIPG Onderzoeksvragenlijst Arbeidsinhoud-WEBA (NOVA-WEBA): constructie en eerste toets op betrouwbaarheid en validiteit [NIPG research questionnaire Job Content-WEBA (NOVA-WEBA): construction and a first test on reliability and validity]. Leiden (The Netherlands): NIPG-TNO, 1992.

37. Houtman ILD, Bloemhoff A, Dhondt S, Terwee T. WEBA en NOVA-WEBA in relatie tot Gezondheid en Welbevinden van Werknemers [WEBA and NOVA-WEBA in relation to health and well-being of employees]. Leiden (The Netherlands): TNO-PG, 1994.

38. Dhondt S, Houtman I. NOVA-WEBA handleiding [NOVAWEBA manual]. Amsterdam: NIA-TNO; 1997.

39. Karasek RA, Pieper CF, Schwartz JE. Job Content Question- naire and user's guide. Revision 1.1. Los Angeles (CA): USCLA; 1985.

40. Karasek R, Brisson C, Kawakami N, Houtman I, Bongers P, Amick B. The Job Content Questionnaire (JCQ): an instrument for internationally comparative assessments of psychosocial job characteristics. J Occup Health Psychol 1998; 3(4):322-55.

41. Houtman ILD, Goudswaard A, Dhondt S, Van der Grinten MP, Hildebrandt VH, Van der Poel EGT. Dutch monitor on stress and physical load: risk factors, consequences, and preventive action. Occup Environ Med 1998;55:73-83.

42. Bergers GPA, Marcelissen FJH, De Wolff CJ. Handleiding Vragenlijst Organisatiestress [manual of the Questionnaire on Organizational Stress]. Nijmegen (The Netherlands): Stress Groep Nijmegen-Psychologie van Arbeid \& Organisatie; 1986.

43. Jöreskog KG, Sörbom D. LISREL 8: user's reference guide. Chicago (IL): Scientific Software International; 1993.

44. Bentler PM, Bonett DG. Significance tests and goodness of fit in the analysis of covariance structures. Psychol Bull 1980;88:588-606.

45. Bentler PM. Comparative fit indexes in structural models. Psychol Bull 1990;107:238-46.

46. Byrne BM. Structural equation modeling with AMOS: basic concepts, applications and programming. Mahwah (NJ): Lawrence Erlbaum Associates; 2001.

47. Zapf D, Dormann C, Frese M. Longitudinal studies in organizational stress research: a review of the literature with references to methodological issues. J Occup Health Psychol 1996;1:145-69.

48. Semmer NK, Zapf D, Greif S. "Shared job strain": a new approach for assessing the validity of job stress measurements. J Occup Organ Psych 1996;69(3):293-311.

49. Semmer NK, Grebner S, Elfering A. Beyond self-report: using observational, physiological, and situation-based measures in research on occupational stress. In: Perrewé PL, Ganster DC, editors. Emotional and physiological processes and positive intervention strategies. Amsterdam, etc: Elsevier; 2004.

50. De Lange AH, Taris TW, Kompier MAJ, Houtman ILD, Bongers PM. The very best of the millennium: longitudinal research on the Demand-Control (Support) Model. J Occup Health Psychol 2003;8:282-305.

51. Mohren DCL, Swaen GMH, Kant IJ, Borm PJA, Galema JMD. Associations between infections and fatigue in a Dutch working population: results of the Maastricht Cohort Study on fatigue at work. Eur J Epidemiol 2001;17:1081-7.

52. De Croon EM, Sluiter JK, Frings-Dresen MHW. Need for recovery after work predicts sickness absence: a 2-year prospective cohort study in truck drivers. J Psychosom Res 2003;55:331-9.

53. Den Dulk L. Work-family arrangements in organisations: a cross-national study in The Netherlands, the United Kingdom and Sweden. Amsterdam: Rozenberg Publishers; 2001.

54. Dikkers JSE, Geurts SAE, den Dulk L, Peper B, Kompier MAJ. Relations among work-home culture, the utilization of work-home arrangements, and work-home interference. Int J Stress Manage 2004;11(4):323-45.

Received for publication: 8 January 2004 